\title{
Electromyographic Analysis of Selected Upper Extremity Muscles during Jump Throwing in Handball
}

\author{
Sherif Ali Taha ${ }^{1}$, Abdel-Rahman Ibrahim Akl ${ }^{2}$, , Mohamed Ahmed Zayed ${ }^{2}$ \\ ${ }^{1}$ Faculty of Physical Education, Kafr El-Sheikh University, Kafr El-Sheikh, Egypt \\ ${ }^{2}$ Faculty of Physical Education, Alexandria University, Alexandria, Egypt \\ Email address: \\ abdelrahman.akl@alexu.edu.eg (Abdel-Rahman I. A.)
}

\section{To cite this article:}

Sherif Ali Taha, Abdel-Rahman Ibrahim Akl, Mohamed Ahmed Zayed. Electromyographic Analysis of Selected Upper Extremity Muscles during Jump Throwing in Handball. American Journal of Sports Science. Vol. 3, No. 4, 2015, pp. 79-84. doi: 10.11648/j.ajss.20150304.13

\begin{abstract}
The purpose of this study was to determine upper extremity selected muscles activity of throwing performance in handball and work-loading to determine the percentage contribution of the muscles that more activation during throwing performance. Five male high level handball players participated in this study were (age: $20.5 \pm 0.53$ years; body mass: $81.00 \pm$ $3.16 \mathrm{~kg}$; height: $186.5 \pm 3.69 \mathrm{~cm})$. The EMG activity of the selected upper extremity muscles was measured using an 16channel surface EMG system (ME6000 telemetric hardware system, Mega Electronics Ltd., FINLAND), Bipolar, Ag/AgCl surface electrodes (SKINTACT, FS-521), Innsbruck, Austria) were placed over the motor point of each muscle, and the EMG signals were acquired at a sampling rate of $1000 \mathrm{~Hz}$ with the MEGAWIN version 3.1-b12 software. Results showed the

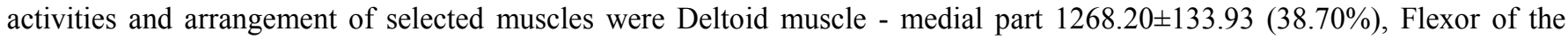
wrist $462.00 \pm 89.04$ (16.30\%), Flexor carpi ulnaris $439.30 \pm 33.87$ (14.40\%), Biceps brachii muscle $364.90 \pm 31.34$ (12.90\%), Rectus abdominis muscle $314.80 \pm 48.94$ (9.70\%), and Pectoralis major muscle $225.90 \pm 36.70$ (8.00\%). The rational for using sEMG to study muscle activation during a standardized jump throwing in handball is to provide a better understanding of muscle activation during this sport specific movement and muscle contributions during jump throwing in handball, and these data may be important for handball's coaches to jump throwing performance training.
\end{abstract}

Keywords: EMG, Handball, Muscle Activation, Upper Limb, Throwing

\section{Introduction}

Handball is an Olympic sport which requires a high level of physical fitness necessary for the relevant activities of the game, and a strenuous contact sport that emphasizes running, jumping, sprinting, throwing, hitting, blocking, and pushing $[1,2]$. Among these, throwing capacity has been highlighted as the key to success [3].

Previous studies in team handball throwing $[4,5,6,7,8,9$, $10,11]$ analyzed standing throws, standing throws with runup, as well as jump throws, and identified the ball release speed as the main performance factor determining the throwing movement. It has been estimated that velocity and precision play a fundamental role in scoring a goal $[6,12]$. Despite the fact that performance improvement is attributed mainly to neural factors, few researchers evaluated simultaneously the changes in performance with the changes in muscle activation using surface electromyography (EMG) [13].
In throwing events, the shoulder and arm musculature is responsible for the propulsion of the object held in the hand as well as for the protection of the surrounding tissues [14]. Muscles participate critically in the execution of human motor tasks. When muscle strength, power, or coordination is impaired, task execution is compromissed [15]. The muscle can perform many mechanical functions. A muscle can develop force and power, and over time produce work output, or it can dissipate mechanical energy if its active fibers are stretched. When its tendon, aponeurosis, and other in- series elastic elements are stretched, energy is stored. The force-length-velocity property of muscle can stabilize movement with its impedance-like function before reflexes become operative $[16,17,18]$. Muscles redistribute the net mechanical energy of the body segments because each muscle force causes reaction forces throughout the body with the net effect being to accelerate some segments and decelerate others [19].

Studies of the neuromuscular system often employ recordings of the electrical activity of skeletal muscle. These 
electromyographic recordings may be of electrical signals detected within a muscle via needle or wire electrodes or from the surface of the skin via surface electrodes. Surface electromyography (EMG) is frequently used to estimate the amount of muscle activation required for specific tasks [20, $21]$ and to examine changes in muscle activation as a result of training and performance [22].

Despite the basic (body mass, body height, and body mass index) and specific (hand) anthropometric characteristics are important to technical and tactical skills [23], but elite performance also demands strength and power in both the upper and the lower limb muscles. So the purpose of this study was to determine upper extremity selected muscles activity of throwing performance in handball and workloading to determine the percentage contribution of the muscles that more activation during throwing performance by using electromyography (EMG).

Electromyographic (EMG) recordings during athletic throwing movements allow for the determination of the timing and quantity of muscle activation, and they are helpful to trainers and therapists for providing athletes with appropriate technical instructions, strength training, injury prevention, and rehabilitation protocols [24].

The EMG signal variables related to the amplitude of the electrical activity (root mean square, i.e. RMS or integrated EMG, i.e. IEMG) is quantified as activity level [25] to more understanding of muscle activation during this sport specific movement and muscle contributions during jump throwing in handball.

\section{Methods}

\subsection{Participants}

Five male high level handball players participated in this study were (age: $20.5 \pm 0.53$ years; body mass: $81.00 \pm 3.16$ $\mathrm{kg}$; height: $186.5 \pm 3.69 \mathrm{~cm})$. They were athletes in the state of Alexandria, Egypt, and participated in regional and national competitions; and they are members of a professional team that plays in the Egyptian handball Super League.

\subsection{Procedures}

A 15 min warm-up was allowed for each participant including general and shoulder-specific mobility exercises, as well as stretching exercises and familiarization trials. The speed-accuracy instruction was selected because it is similar to the competition requirements, where the player attempts to throw as fast and accurately as possible in order to score a goal. The participants completed jump throws from the $7 \mathrm{~m}$ penalty line using a standard handball for men after 3 steps running. A total of 5 successful trials were recorded for each participant with one minute rest between trials as in the studies of Oliver, Plummer, \& Keeley [26] and Rojas et al. [27], and the best two trials were selected to analysis for each participant.

The EMG activity of the selected upper extremity muscles (Deltoid muscle - medial part (D-m), Biceps brachii muscle (BB), Flexor of the wrist (FW), Flexor carpi ulnaris (FCU), Pectoralis major muscle (PM), and Rectus abdominis muscle (RA)) was measured using an 16-channel surface EMG system (ME6000 telemetric hardware system, Mega Electronics Ltd., FINLAND).

After skin preparation (shaving, gently scrubbing, and cleaning with alcohol), Bipolar, $\mathrm{Ag} / \mathrm{AgCl}$ surface electrodes (SKINTACT, FS-521), Innsbruck, Austria) were placed over the motor point of each muscle. All EMG signals were visually monitored during the collection of data, and the EMG signals were acquired at a sampling rate of $1000 \mathrm{~Hz}$ with the MEGAWIN version 3.1-b12 software. EMG fullwave rectification by RMS Averaging. Averaged RMS value is calculated according to the following equation:

$$
\text { RMSvalue }[I]=\sqrt{\frac{\sum_{i=n}^{n+N-1}\left|\operatorname{Data}_{\text {Raw }}[i]\right|^{2}}{N}}
$$

Where: $\mathrm{I}=$ index of RMS data

$\mathrm{i}=$ index of raw data

$\mathrm{N}=$ number of data points in RMS calculation

$\mathrm{n}=[1, \mathrm{~N}+1,2 \mathrm{~N}+1, \ldots] .[28]$

\subsection{Statistical Analysis}

Data are expressed as means \pm standard deviations by IBM SPSS Statistics 21 was used to examine the descriptive statistics.

\section{Results}

The mean values and standard deviations of the muscles activity during jump throwing performance are presented in Table 1. The Deltoid muscle - medial part had greater activity during performance, then the Flexor of the wrist muscle is the second muscle by activity, Flexor carpi ulnaris muscle, Biceps brachii muscle, Rectus abdominis muscle, and in the last Pectoralis major muscle.

Table 1. Descriptive values (Minimum, Maximum, Mean, and Std. Deviation) of muscle activity during jump throwing in handball.

\begin{tabular}{|c|c|c|c|c|}
\hline Muscles activity & Minimum & Maximum & Mean & Std. Deviation \\
\hline Deltoid muscle - medial part $(\mu v)$ & 1049.00 & 1447.00 & 1268.20 & 133.93 \\
\hline Biceps brachii muscle $(\mu \mathrm{v})$ & 316.00 & 435.00 & 364.90 & 31.34 \\
\hline Flexor of the wrist $(\mu \mathrm{v})$ & 345.00 & 591.00 & 462.00 & 89.04 \\
\hline Flexor carpi ulnaris $(\mu v)$ & 405.00 & 518.00 & 439.30 & 33.87 \\
\hline Pectoralis major muscle $(\mu v)$ & 170.00 & 283.00 & 225.90 & 36.70 \\
\hline Rectus abdominis muscle $(\mu v)$ & 260.00 & 414.00 & 314.80 & 48.94 \\
\hline
\end{tabular}




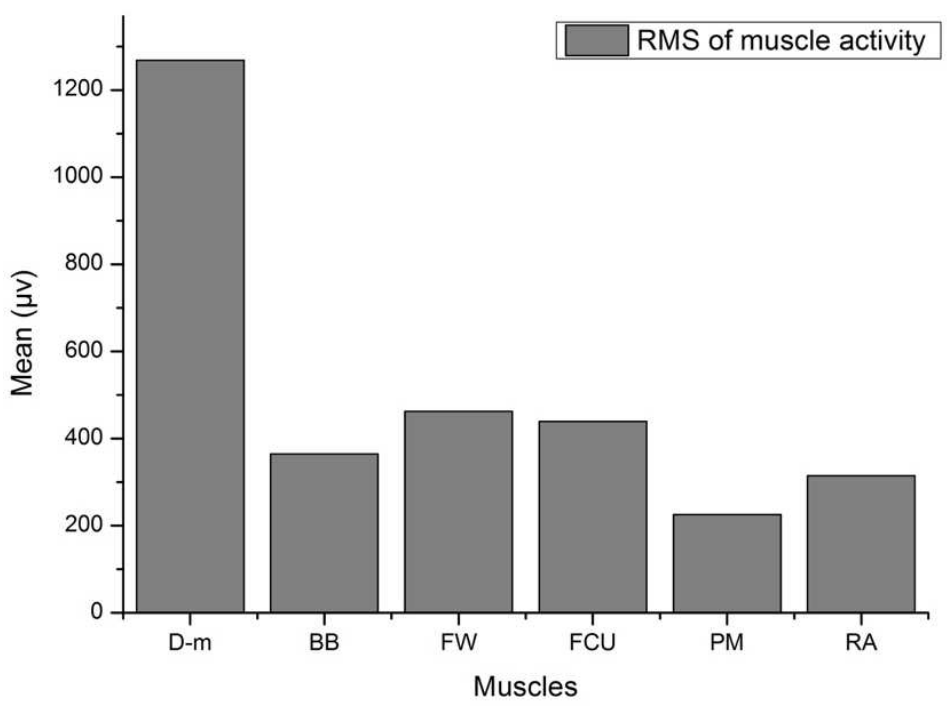

Figure 1. Muscle activity: Deltoid muscle - medial part (D-m), Biceps brachii muscle (BB), Flexor of the wrist (FW), Flexor carpi ulnaris (FCU), Pectoralis major muscle (PM), and Rectus abdominis muscle (RA) during jump throwing in handball.

And the mean values and standard deviations of the workloading during jump throwing performance are presented in Table 2. That demonstrate muscles contributions during performance are following, The Deltoid muscle - medial part had greater contribution during performance, the Flexor of the wrist muscle, Flexor carpi ulnaris muscle, Biceps brachii muscle, Rectus abdominis muscle, and in the last Pectoralis major muscle.

Table 2. Descriptive values (Minimum, Maximum, Mean, and Std. Deviation) of work-loading during jump throwing in handball.

\begin{tabular}{lllll}
\hline Muscles Work-loading & Minimum & Maximum & Mean & Std. Deviation \\
\hline Deltoid muscle - medial part (\%) & 35.00 & 44.00 & 38.70 & 3.16 \\
Biceps brachii muscle (\%) & 10.00 & 15.00 & 12.90 & 1.45 \\
Flexor of the wrist (\%) & 13.00 & 21.00 & 16.30 & 2.67 \\
Flexor carpi ulnaris (\%) & 13.00 & 17.00 & 14.40 & 1.26 \\
Pectoralis major muscle (\%) & 6.00 & 9.00 & 8.00 & 1.05 \\
Rectus abdominis muscle (\%) & 7.00 & 14.00 & 9.70 & 1.89 \\
\hline
\end{tabular}

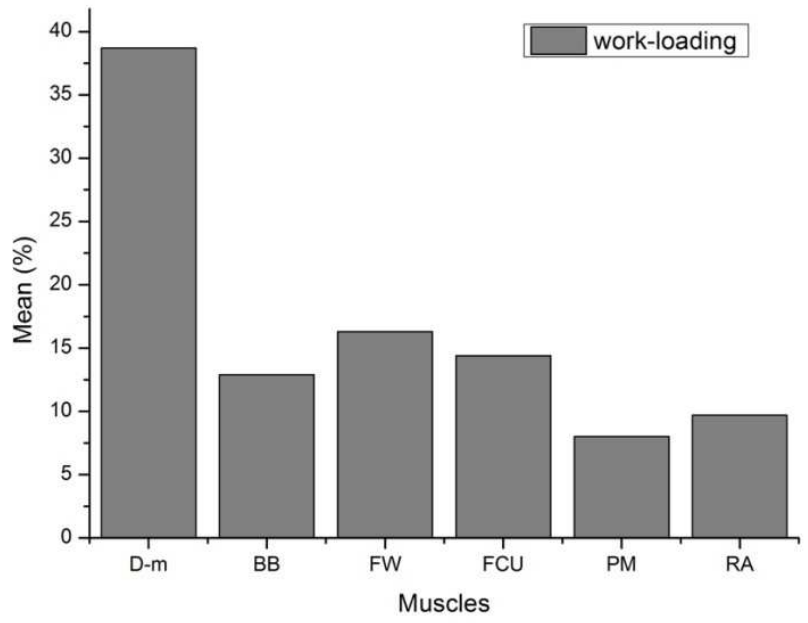

Figure 2. Work-loading of muscles: Deltoid muscle - medial part (D-m), Biceps brachii muscle (BB), Flexor of the wrist (FW), Flexor carpi ulnaris (FCU), Pectoralis major muscle (PM), and Rectus abdominis muscle (RA) during jump throwing in handball.

\section{Discussion}

Handball is one of games that require a high level of fitness beside the technical and mental preparation, and it's one of the most sports that required physical fitness elements such as strength and power and speed, especially in the upper extremity to adopt a lot of skills on the efficiency and effectiveness of the muscular strength of the upper extremity.

And jump throwing in handball is the most important skill for their impact and effectiveness during the games where they constitute more than $80 \%$ of the throws number during the games [29].

And the most important muscles of upper extremity that 
contribute to this skill that working on the joints of arm throwing (shoulder - elbow - wrist), and emphasize the importance of muscular work balance of these muscles not only for better performance level of skill, but also to prevent injuries, where previous studies indicated to the injury rate in high level players were 0.6-2.4 injury per 1,000 hours of training and 13.3-108 injury per 1,000 hours during the games [30, 31, 32, 33].

So the purpose of this study was determine muscular activity of selected muscles of the upper extremity while performing jump throwing in handball.

The results indicated that the Deltoid muscle - medial part is the most active during the performance, due to the deltoid muscle which is working to start moving the shoulder joint that work in a big range of motion during jump throwing in handball, and cause a subscription that muscle during the performance significantly and the results showed that from the high rate of activity of this muscle than other muscles which is confirmed by studies [24, 34, 35, 36] that deltoid muscle - medial part is one of more active muscles during performance throwing skills, and also to maintain the shoulder joint during movement or abduction position [37, 38].

The results show that the Flexor of the wrist, Flexor carpi ulnaris are the second and third, due to the fact that these two muscles work to catch movements by hands on the ball, as is evident from the beginning of the performance that the player catch the ball, resulting in the movement of muscle contraction from the beginning of the throwing until the moment the ball out of the player's hand, as they work for directing the ball through moving wrist joint at the ball release $[39,40]$.

And the results indicated that the muscular activity of Biceps brachii in fourth place due to the fact that the muscle is working to move the elbow joint of the maximum swing arm to stabilize it until the moment before throwing to the goal, and the muscle move the joint forward to increase the throwing arm velocity and through it help in the stability of the shoulder [24]. As well as the basic function of this muscle is flexion of the elbow joint and help of shoulder joint flexion [41].

The present EMG results indicated that the EMG activity of the Rectus abdominis muscle is in the fifth among the selected muscle and that muscle work in the case of contraction from the beginning of takeoff phase during the throwing, where they are working on hyperextension of lumbar spine, which helps the player to take off higher than the opponent and it's one of important muscles that contract through the cocking phase in throwing [42].

The results show that the Pectoralis major muscle ranked last, although it's a big and effective muscle in the upper extremity movements due to the quality of the phase measured from the moment of maximum arm swing to the moment of ball release, resulting in activity of muscle is greater in arm muscles than Pectoralis major muscle, as a result of catch the ball and carry it from the beginning of the performance to the end where they are moving the arm from back to the top and front $[34,36,43]$, and also because the jump throwing skill in handball be arm movement rather than forward to the inside, where the activity of the pectoralis major muscle increases when the arm do internal movement, where they work on the arm adduction movements, and so was its less according to the nature of the performance of the jump throwing skill [24].

\section{Conclusions}

The purpose of this study was determine muscular activity of selected muscles of the upper extremity while performing jump throwing in handball. Results showed the activities and arrangement of selected muscles were Deltoid muscle medial part $1268.20 \pm 133.93(38.70 \%)$, Flexor of the wrist $462.00 \pm 89.04$ (16.30\%), Flexor carpi ulnaris $439.30 \pm 33.87$ (14.40\%), Biceps brachii muscle 364.90土31.34 (12.90\%), Rectus abdominis muscle $314.80 \pm 48.94$ (9.70\%), and Pectoralis major muscle $225.90 \pm 36.70(8.00 \%)$. Finally, the rational for using sEMG to study muscle activation during a standardized jump throwing in handball is to provide a better understanding of muscle activation during this sport specific movement and muscle contributions during jump throwing in handball, and these data may be important for handball's coaches to jump throwing performance training.

\section{References}

[1] Gorostiaga EM, Granados C, Ibanez J, Gonzalez-Badillo JJ, Izquierdo M. Effects of an entire season on physical fitness changes in elite male handball players. Med Sci Sports Exerc 2006; 38: 357-366.

[2] Rivilla-García J, Navarro F, Grande I, Ignatova AS, Sampedro J. Differences throwing capacity between senior and u-18 men handball players. Serb J Sports Sci 2010; 4: 145-151.

[3] Elliott BC, Armour J. The penalty throw in water polo: a cinematographic analysis. J Sports Sci 1988; 6: 103-114.

[4] Fleck SJ, Smith SL, Craib MW, Denahan T, Snow RE, Mitchell MR. Upper extremity isokinetic torque and throwing velocity in team handball. J Strength Cond Res 1992; 6: 120124.

[5] Fradet L, Botcazou M, Durocher C, Cretual A, Multon F, Prioux J, et al. Do handball throws always exhibit a proximalto-distal segmental sequence? J Sports Sci 2004; 22: 439-447.

[6] Gorostiaga EM, Granados C, Ibanez J, Izquierdo M. Differences in physical fitness and throwing velocity among elite and amateur male handball players. International Journal of Sports Medicine 2005; 26: 225-232.

[7] Joris HJ, van Muyen AJ, van Ingen Schenau GJ, Kemper HC. Force, velocity and energy flow during the overarm throw in female handball players. J Biomech 1985; 18: 409-414.

[8] Pori P, Bon M, Sibila M. Jump shot performance in team handball. A kinematic model evaluated on the basis of expert modeling. International Journal of Fundamental and Applied Kinesiology 2005; 37: 40-49. 
[9] Van Den Tillaar R, Ettema G. A force-velocity relationship and coordination patterns in overarm throwing. Journal of sports science \& medicine 2004; 3: 211-219.

[10] Van Den Tillaar R, Ettema G. A three-dimensional analysis of overarm throwing in experienced handball players. J Appl Biomech 2007; 23: 12-19.

[11] Wagner H, Muller E. The effects of differential and variable training on the quality parameters of a handball throw. Sports biomechanics / International Society of Biomechanics in Sports 2008; 7: 54-71.

[12] Bayios IA, Boudolos KD. Accuracy and throwing velocity in handball. 16 International Symposium on Biomechanics in Sports. Konstanz - Germany1998. p. 55-58.

[13] Jones P, Lees A. A biomechanical analysis of the acute effects of complex training using lower limb exercises. J Strength Cond Res 2003; 17: 694-700.

[14] Rousanoglou EN, Noutsos KS, Bayios IA, Boudolos KD. Electromyographic Activation Patterns during Handball Throwing By Experts and Novices. J Athl Enhancement 2014; 3: $1-8$.

[15] Zajac FE. Understanding muscle coordination of the human leg with dynamical simulations. J Biomech 2002; 35: 10111018 .

[16] Brown IE, Loeb GE. A reductionist approach to creating and using neuromusculoskeletal models. New York: Springer; 2000 .

[17] Gerritsen KG, van den Bogert AJ, Hulliger M, Zernicke RF. Intrinsic muscle properties facilitate locomotor control - a computer simulation study. Motor Control 1998; 2: 206-220.

[18] Loeb GE, Brown IE, Cheng EJ. A hierarchical foundation for models of sensorimotor control. Exp Brain Res 1999; 126: 118 .

[19] Zajac FE, Neptune RR, Kautz SA. Biomechanics and muscle coordination of human walking. Part I: introduction to concepts, power transfer, dynamics and simulations. Gait \& posture $2002 ; 16: 215-232$.

[20] Soderberg GL, Cook TM. An electromyographic analysis of quadriceps femoris muscle setting and straight leg raising. Physical therapy 1983; 63: 1434-1438.

[21] Veiersted KB, Westgaard RH, Andersen P. Pattern of muscle activity during stereotyped work and its relation to muscle pain. International archives of occupational and environmental health 1990; 62: 31-41.

[22] Narici MV, Roi GS, Landoni L, Minetti AE, Cerretelli P. Changes in force, cross-sectional area and neural activation during strength training and detraining of the human quadriceps. European journal of applied physiology and occupational physiology 1989; 59: 310-319.

[23] Visnapuu M, Jurimae T. Handgrip strength and hand dimensions in young handball and basketball players. J Strength Cond Res 2007; 21: 923-929.

[24] Escamilla RF, Andrews JR. Shoulder muscle recruitment patterns and related biomechanics during upper extremity sports. Sports Med 2009; 39: 569-590.

[25] Ozgunen KT, Celik U, Kurdak SS. Determination of an Optimal Threshold Value for Muscle Activity Detection in
EMG Analysis. Journal of sports science \& medicine 2010; 9: 620-628.

[26] Oliver GD, Plummer HA, Keeley DW. Muscle activation patterns of the upper and lower extremity during the windmill softball pitch. J Strength Cond Res 2011; 25: 1653-1658.

[27] Rojas IL, Provencher MT, Bhatia S, Foucher KC, Bach BR, Jr., Romeo AA, et al. Biceps activity during windmill softball pitching: injury implications and comparison with overhand throwing. Am J Sports Med 2009; 37: 558-565.

[28] Electronics M. MegaWin 3.0 Software User Manual. KUOPIO, FINLAND: Mega Electronics Ltd; 2008. p. 1-197.

[29] Darwish K, Morsi K, Abozeid E. Measurement, Evaluation and Game analysis in Handball. Cairo, Egypt: Book Center; 2002.

[30] Edouard P, Degache F, Oullion R, Plessis J-Y, Gleizes-Cervera S, Calmels P. Shoulder Strength Imbalances as Injury Risk in Handball. International Journal of Sports Medicine 2013; 34: 654-660.

[31] Langevoort G, Myklebust G, Dvorak J, Junge A. Handball injuries during major international tournaments. Scand J Med Sci Sports 2007; 17: 400-407.

[32] Nielsen AB, Yde J. An epidemiologic and traumatologic study of injuries in handball. Int J Sports Med 1988; 9: 341-344.

[33] Seil R, Rupp S, Tempelhof S, Kohn D. Sports injuries in team handball. A one-year prospictive study of sixteen men's senior teams of a superior nonprofessional level. Am J Sports Med 1998; 26: 681-687.

[34] Peng H, Peng H, Huang C. Electromyographic analysis of standing shot throw ISB Sixth Congress - ASB 29th Annual Meeting. Cleveland, Ohio2005.

[35] Stephen M, Colin A, Terry R. EMG analysis of shoulder muscle fatigue during resisted isometric shoulder elevation. Journal of Electromyography and Kinesiology 2007; 17: 153159 .

[36] Tsai C-L, Yang C-C, Mei-Shiu Lin K-SH, ShawShiun C. The surface EMG activity of the upper limb muscles of badminton forehand and backhand smashes. XXIV ISBS Symposium Salzburg - Austria 2006.

[37] Digiovine NM, Jobe FW, Pink M, Perry J. An electromyographic analysis of the upper extremity in pitching. J Shoulder Elbow Surg 1992; 1: 15-25.

[38] Sakaki Y, Kaneko F, Watanabe K, Kobayashi T, Katayose M, Aoki N, et al. Effects of different movement directions on electromyography recorded from the shoulder muscles while passing the target positions. Journal of Electromyography and Kinesiology 2013; 23: 1362-1369.

[39] Brekaa M, Akl A-R. Fundamentals of EMG measurement (Part 1). Alexandria, Egypt: Monshaat Elmaaref publisher; 2014.

[40] Lippert LS. Clinical Kinesiology and Anatomy. Fifth ed. United States of America: F. A. Davis Company; 2011.

[41] Bonnel F. Les muscles de la racine du membre supérieur (muscles of the root of the upper limb). In: Bonnel F, Chevrel JP, Outrequin G, editors. Anatomie clinique. Paris: SpringerVerlag; 1991. p. 52-66. 
[42] Balius R, Pedret C, Pacheco L, Gutierrez JA, Vives J, Escoda J. Rectus abdominis muscle injuries in elite handball players: management and rehabilitation. Open access journal of sports medicine 2011; 2: 69-73.
[43] Glousman R, Jobe F, Tibone J, Moynes D, Antonelli D, Perry J. Dynamic electromyographic analysis of the throwing shoulder with glenohumeral instability. The Journal of bone and joint surgery American volume 1988; 70: 220-226. 